\title{
Outcomes of Snakebite Envenomation in Children
}

\section{Shrestha BM ${ }^{1}$}

${ }^{1}$ Dr. Binod Man Shrestha, MBBS, MD. Professor in Paediatrics (NAMS). Chief Consultant Paediatrician Kanti Childre's Hospital, Maharajgunj, Kathmandu, Nepal.

Adress for Correspopndence: Dr. BM Shrestha, E-mail: drbinod@yahoo.com

\begin{abstract}
Introduction: Snakebite is a medical emergency, and is considered to be one of the major public health hazards in the Terai and inner-Terai regions of Nepal.Very few studies have been conducted so far in Nepal to highlight the epidemiology of snakebite in children. Aim: To review the pattern and characteristics of snakebites in children, focusing primarily on the outcomes, fatality and risk factors for death. Settings: An emergency department of a 136-bedded secondary care-referral hospital (Lumbini Zonal Hospital) situated at Butwal in the Western Nepal. Methodology: The study was carried out in 152 children aged < 15 years old, who got anti-snake venom (ASV) over a period of 48 months. Diagnosis of snakebite envenomation was based on clinical ground. Results: Children over 5 years of age constituted the highest number $(87 \%)$ of cases. Peak incidence of poisoning $(71 \%)$ was observed during the months of Asadh- Bhadra (June-September). Most of the bites (61\%) were by unidentified snakes, most commonly $(91 \%)$ on the extremities. Snakebite envenomation occurred more frequently (52\%) during night time. $85 \%$ of children had local or systemic complications, commonest being respiratory paralysis(92/152). Case fatality rate (CFR) was $28 \%$. Risk factors for death were: age < 5 years; bites by unidentified snakes and kraits and bites on ears \& unknown sites. Conclusion: Compared with adults, children with snake envenomation have higher morbidity and mortality, which can be minimized by early diagnosis, appropriate treatment and close monitoring of children on ventilation for the timely management of complications. Emphasis should be given on developing a standard management protocol in children.
\end{abstract}

Keywords: Snakebite, Envenomation, Children, Outcomes and Nepal

\section{Introduction}

Snakebite is a preventable life-threatening medical accident, the dangers of which are amplified in children possibly because of a higher ratio of injected venom to body mass. Venomous snakebite is an important public health hazard in tropical and subtropical countries ${ }^{1,2,3}$, including Nepal. Snakebite envenomation often leads to premature death of children mostly from rural areas. Studies have shown that children under 15 years old account for two-third to three-fourth of the total cases of snakebite ${ }^{4,5}$. Children are at risk of sustaining snakebite mainly because of their curiosity about the unknown creatures, innocent act of invading the reptile's space, and habit of barefoot walking particularly in the darkness.

Although there are greater than 3,000 known species of snakes in the world, only 200 are poisonous to humans ${ }^{6} .90 \%$ of these snakes are members of one of three families ${ }^{6}$ : the Elapidae (cobras, Kraits etc); the Viperidae (pit and Russel's vipers); the Hydrophidae (poisonous sea-snakes). In Nepal, out of 77 species of snakes recorded, 22 are poisonous ${ }^{5}$. Common venomous snakes in the 26 Terai and inner-Terai districts of Nepal are Kraits, cobras and vipers ${ }^{5}$.

Snake venom is a mixture of 20 enzymes and polypeptide toxins. Elapid snake venom contains bungarotoxin, a neurotoxin, which blocks the nerve transmission at the neuromuscular junction (akin to d-tubocurarin $)^{7,8}$. Death following Elapid snakebite envenomation is typically due to respiratory paralysis or depression.

It is important to remember that not all bites in children are by snakes. Moreover greater than $80 \%$ 
bites are by non-poisonous snakes in children ${ }^{6}$. Even after bites by the venomous snakes, $20-80 \%$ of victims may have little or no envenomation at all ${ }^{9,10,11 .}$

Instantaneous death possibly due to cardiac arrhythmia, acute myocardial infarction or cardiac arrest in some persons may occur due to thought or fear of threat of death just on sighting the hooded cobra without a bite ${ }^{12}$. Anxiety and tachycardia following venomous snakebite occasionally accelerates the rapid absorption of venom into circulation, precipitating the cardiorespiratory arrest ${ }^{12}$. This phenomenon is, however not seen in children as they are unaware of death ${ }^{7}$.

\section{Materials and methods}

A hospital-based prospective study was conducted in 152 children under 15 years old, who were treated for snake envenomation in the emergency department of Lumbini Zonal Hospital (LZH), Butwal during a period of 48 months, starting from 2062-04-01 to 2066-0332. LZH is a 136-bedded secondary level-care referral hospital in the western Nepal. Only cases of snakebite receiving ASV were included in this study. Diagnosis of envenomation was based completely on clinical ground (bilateral ptosis, ophthalmoplegia, salivation etc). Venom detection kit was not used at all in this study, because of its unavailability in Nepal. Data so collected were analyzed for age, sex, month of bite, site of bite, time of bite, type of biting snakes, clinical outcomes, CFR and risk factors for death etc.

Time of bite was grouped as morning (6am-12pm), afternoon (12pm-6pm) or night (6pm-6am).

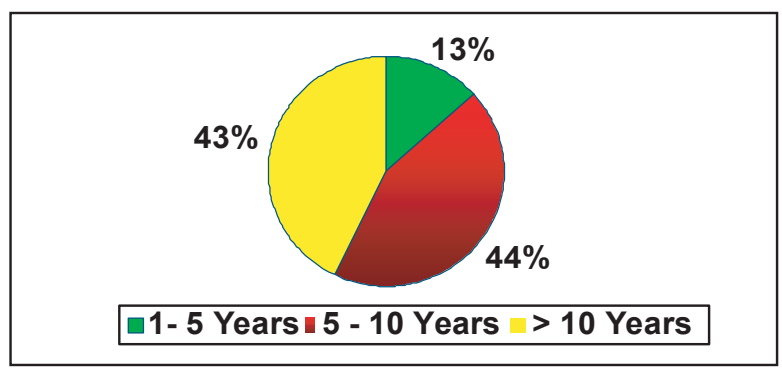

Fig 1: Showing age incidence $(n=152)$

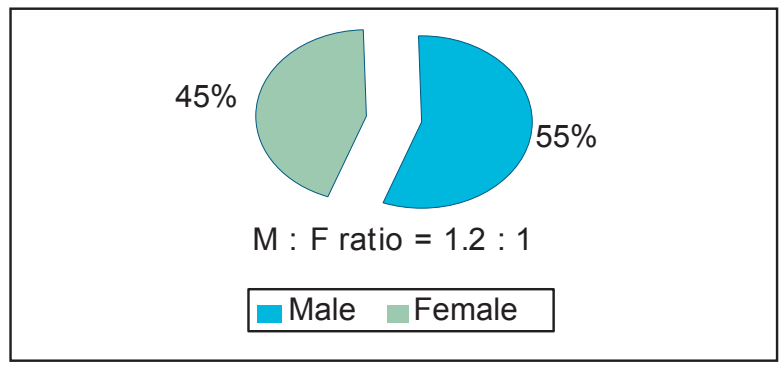

Fig 2: Showing sex incidence $(n=152)$

\section{Results}

Analysis of data on 152 children receiving ASV revealed the following findings:

Maximum (87\%) incidence of poisoning was seen in children $>5$ years old. Average age of children was 8.8 years (range: 17 months to 14 years). Pre-school aged children constituted $13 \%$ of snakebite envenomation.

Boys (55\%) predominated girls $(45 \%)$

$71 \%$ of bites occurred in Asadh- Bhadra (JuneSeptember)

$91 \%$ bites occurred on the extremities with $60 \%$ bites being on hands and feet.

$60 \%$ of the venomous bite occurred during night times.

$60 \%$ of bites were by unidentified/unknown snakes. In $40 \%$ of cases, where the biting snakes were identified, the majority $(74 \%)$ were by Kraits.

The CFR among the venomous bites was $28 \%$.

Majority of bite (61\%) were complicated by respiratory paralysis needing intubation and ventilation.

There was $100 \%$ site-specific fatality with bites on the ear: fatality rate was higher $(40 \%)$ with bite on unknown site. Risk of death in $U_{5}$ children was higher $(50 \%)$. Risk of death either due to unidentified snakes or to Kraits was double as compared to cobra.

Table 1: Showing Complications (Clinical Outcomes) (No complications in 22/152 children)

\begin{tabular}{|l|c|}
\hline Complications & Number (\%) \\
\hline $\begin{array}{l}\text { Respiratory Paralysis needing } \\
\text { intubation / ventilation }\end{array}$ & $92(61 \%)$ \\
\hline Cellulitis & $16(11 \%)$ \\
\hline Skin necrosis / gangrene & $11(7 \%)$ \\
\hline Intubation complications & $8(5 \%)$ \\
\hline $\begin{array}{l}\text { Hypokalaemia leading to } \\
\text { quadriparesis }\end{array}$ & $4(3 \%)$ \\
\hline $\begin{array}{l}\text { Kerato - conjunctivitis (corneal } \\
\text { opacity) }\end{array}$ & $2(1 \%)$ \\
\hline Gastro - intestinal bleeding & 1 \\
\hline
\end{tabular}




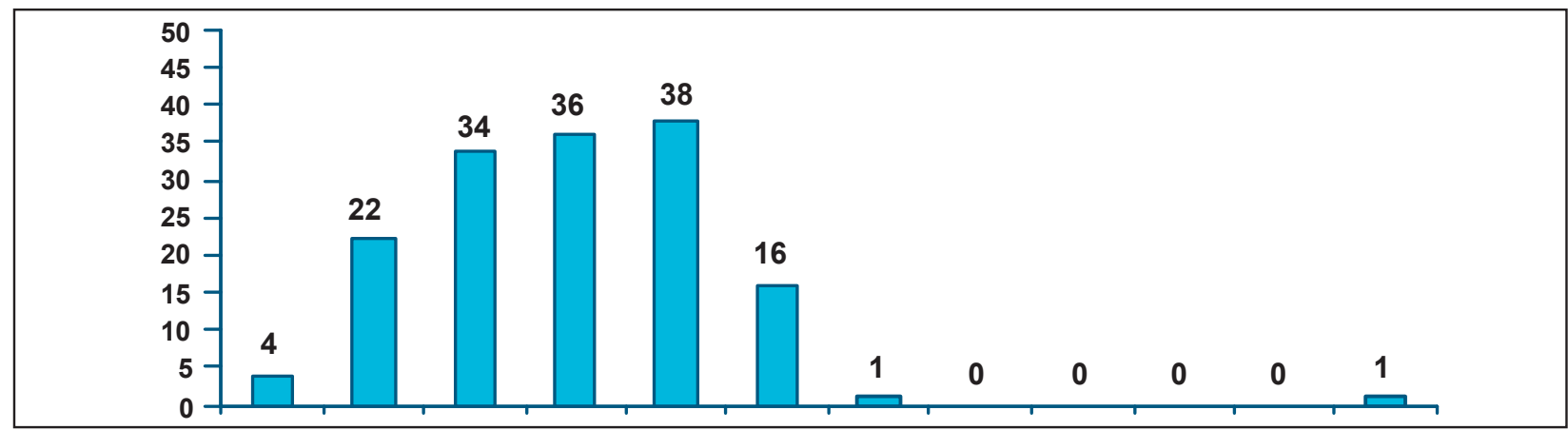

Fig 3: Showing monthly incidence $(n=152)$

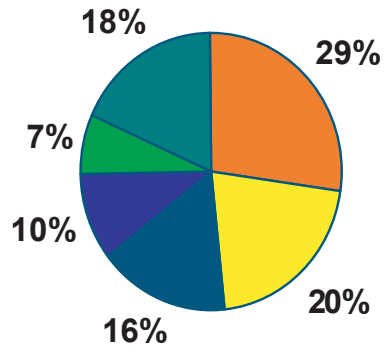

$\square$ Hand $\square$ Foot / Toe $\square$ Leg $\square$ Finger $\square$ Other* $^{*}$ Unknown

Fig 4: Showing site of bite $(n=152)$

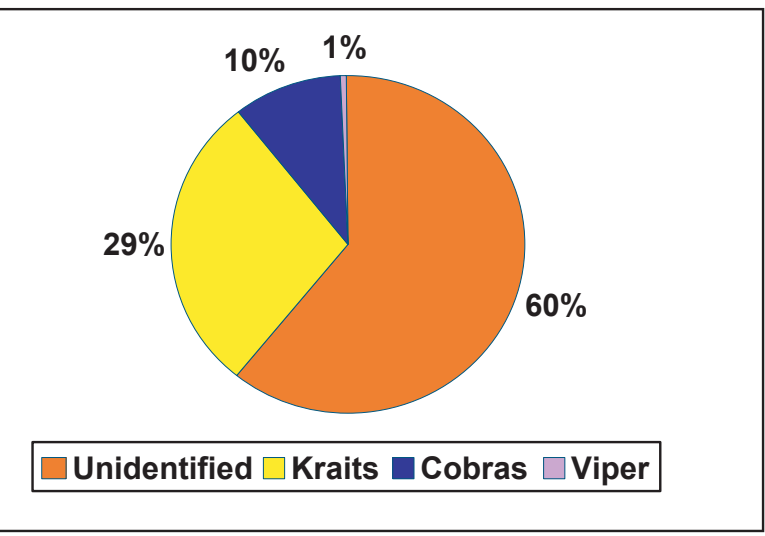

Fig 6: Showing type of biting snakes $(n=152)$

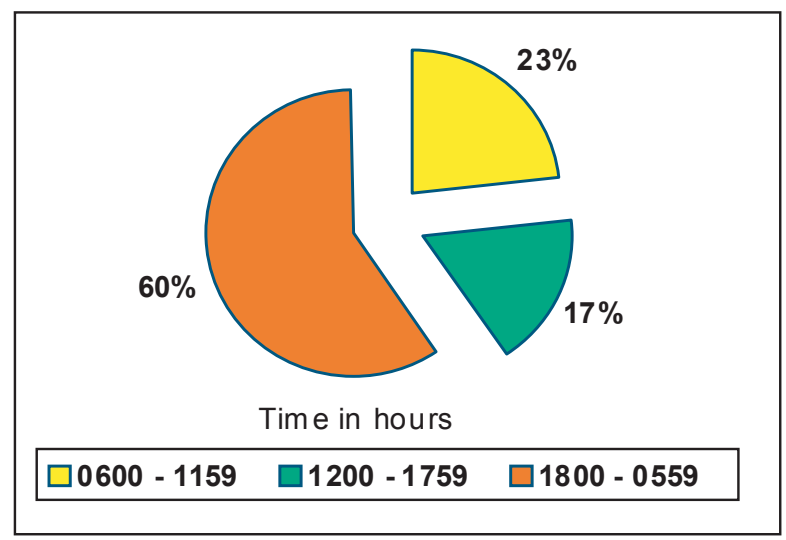

Fig 5: Showing time of bite $(n=133)$

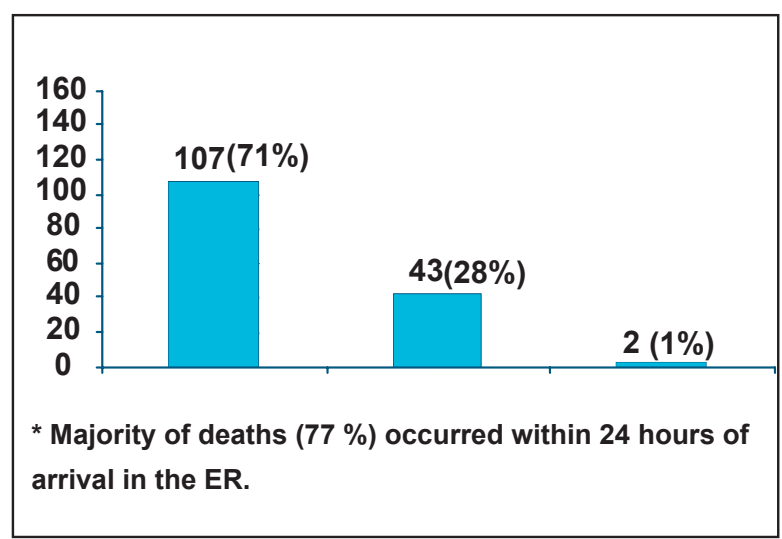

Fig 7: Showing outcome $(n=152)$

Table 2: Showing risk factors for death $(n=43)$

\begin{tabular}{|l|r|r|}
\hline Risk Factors & & Risk (\%) \\
\hline \multirow{3}{*}{ Age (in years) } & $1-5$ & 50 \\
\cline { 2 - 3 } & $5-10$ & 27 \\
\cline { 2 - 3 } & Male & 23 \\
\hline \multirow{3}{*}{ Type of snake } & Female & 27 \\
\cline { 2 - 3 } & Kraits & 30 \\
\hline \multirow{3}{*}{ Site of bite } & Cobras & 27 \\
\cline { 2 - 3 } & Unidentified & 13 \\
\cline { 2 - 3 } & Hand and finger & 30 \\
\cline { 2 - 3 } & Foot /toe & 30 \\
\cline { 2 - 3 } & Leg & 23 \\
\cline { 2 - 3 } & Unknown & 24 \\
\cline { 2 - 3 } & & 100 \\
\cline { 2 - 3 } & & 39 \\
\hline
\end{tabular}




\section{Figures of possible complications}

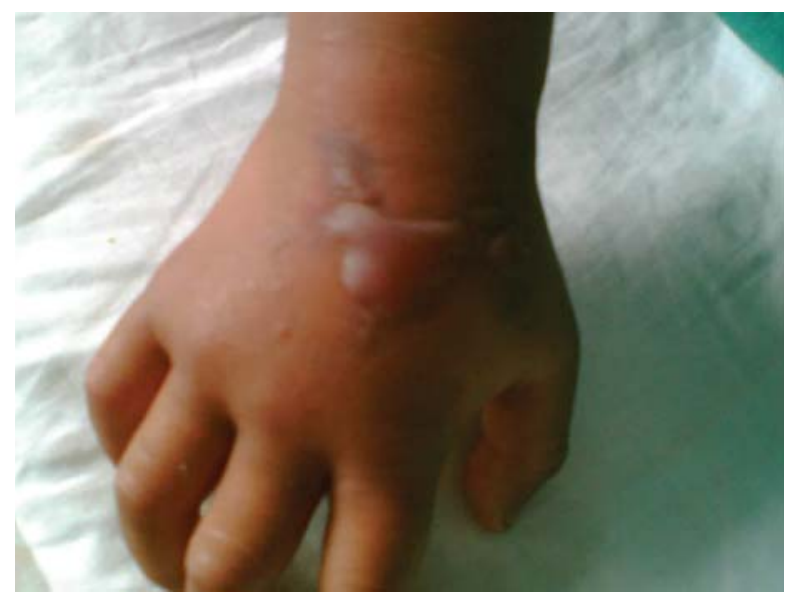

Fig 8 : Blister/Bulla

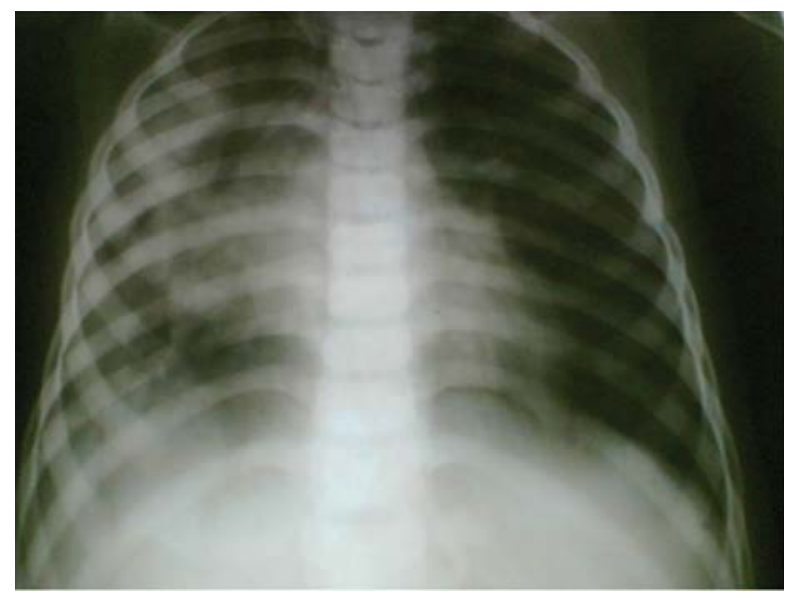

Fig 9: Pneumonia following intubation

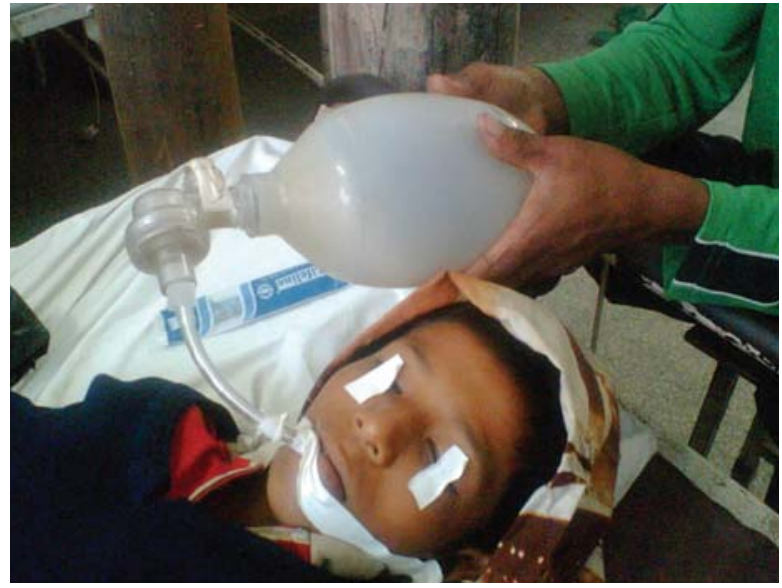

Fig 10: Acute respiratory paralysis needing bag and tube ventilation

\section{Discussion}

Present study has clearly shown the highest (87\%) incidence of snake envenomation in children over 5 years old. Pre-school aged (0-5 yr) children in this study comprised of $13 \%$ of victims in contrast to $35 \%$ in a

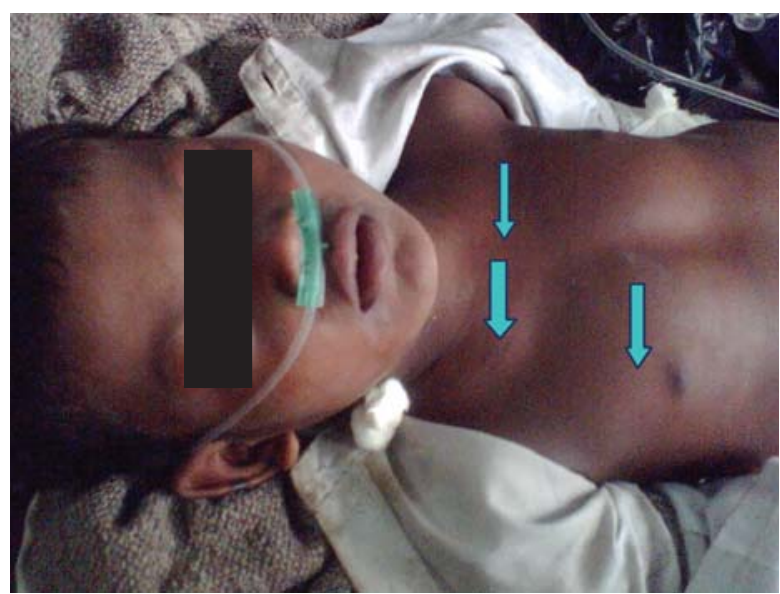

Fig 11: Sub-cutaneous emphysema following intubation

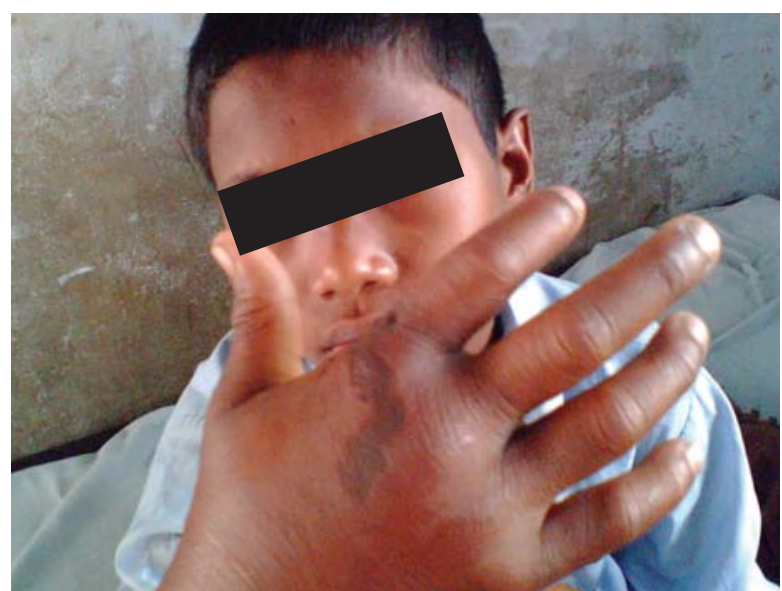

Fig 12: Hand necrosis and cellulitis

previous study done by Jamieson and Pearn ${ }^{14}$, who found the prepubescent boys as the highest "at-risk group" for snakebite. Children over 5 years are at risk of snakebite because they are involved more in outdoor games. Furthermore, the older children in Terai are given the responsibility of carrying out the outdoor activities such as grass-cutting, cattle-grazing and firewoodcollecting etc. Incidence of poisoning was slightly higher in boys $(55 \%)$ than in girls $(45 \%)$. Finding of male predominance seen also in other studies ${ }^{4,14}$ probably relates to the behavior patterns of boys ${ }^{4}$. Saborio et al found no significant gender differences ${ }^{15}$.

Current study showed maximum snakebites (73\%) with envenomation occurring during the rainy/ monsoon season, Jestha to Bhadra (May - September). During this season snakes come out of their shelter because of increased humidity and warmth. This characteristic seasonal pattern of snakebite was also reported in other studies $^{1,4,16}$.

Most of the victims (nearly $61 \%$ ) could not identify the biting snakes. This event denotes either the lack of 
knowledge of children about snakes or poor visibility due to nocturnal bites while sleeping and to walking in darkness. Krait bites mostly occurring at night are usually less painful and the victims forget the local pain because of blunting of reflexes during sound sleep $p^{1,11,17}$

In $91 \%$ of cases the snake had bitten the extremities with $59 \%$ of these bites being on the hands and feet. Curious young children, while playing put their fingers/ hands into the hiding places of snakes such as holes, pits etc. Similarly older children, while cutting grass sustain bites on hands. This finding is similar to that of Currie et al who found $100 \%$ bites on the extremities with $71 \%$ of the bites being on the ankle or below. Some other studies found $70-86 \%$ bites occurring on the lower extremities $^{1,4,14,15,18,19}$, which were possibly because of accidental stampede while walking in the darkness ${ }^{1}$.

Current study showed more frequent (52\%) bites at night time between $6 \mathrm{pm}$ and $6 \mathrm{am}$. This finding is similar to that of Campbell ${ }^{20}$ while in contrast to the finding of Currie et al $(15 \%)^{4}$. Barefoot walking in darkness without using light and sleeping on the ground at night are the risk factors for sustaining nocturnal bites. Most of the bites where the time of bite is not known $(12 \%$ in the present study) do occur at night, and are likely by Kraits.

Majority of children (85\%) following snakebite envenomation developed local or systemic complications. Respiratory paralysis/ failure needing intubation and ventilation occurred in nearly $61 \%(92 / 152)$ of cases. CFR in the current study was quite high (28\%), where as in other studies it varied from $0-14 \% 1,4,18,20$, and 21 . High CFR in children, as in this study is mainly because children sustain a more severe envenomation as a result of increased venom: body mass ratio ${ }^{22}$. Conversely the larger adult body mass may provide a diluent for the snake toxin, theoretically causing a less potent envenomation ${ }^{23}$. Moreover, children seem to have more serious complications than adults, and therefore need a higher dose of $\mathrm{ASV}^{24}$. Furter more, in this study only cases getting ASV were included so as to look at the real morbidity and mortality of snakebites.

The major risk factors for death in this study were: age $<5$ years $(50 \%)$; unidentified snakes \& kraits $(29 \%)$ and bites on ears (100 \%) followed by unknown site of bite $(40 \%)$. In children $<5$ years old, either reporting is late or diagnosis of bite is difficult. Similarly treatment of bites by unidentified snakes or kraits is mostly very late because of failure to diagnose biting early. More over, krait venom is 10 times more lethal than cobra venom. Bites on ears or hands/fingers lead to rapid absorption of venom into circulation, with consequent higher mortality.

\section{Conclusion}

Compared with adults, children with snake envenomation have higher morbidity and mortality, which can be minimized by early diagnosis, appropriate treatment and close monitoring of children particularly those on manual ventilator for timely management of complications.

\section{Recommendations}

Emphasis for the treatment of snakebite in children of Nepal should further be given on the following:

1. Development of a standard management protocol in children.

2. Health education about preventive and improved first-aid measures. and

3. Inclusion of course on snake envenomation in graduate and post-graduate medical training.

Acknowledgement: I am grateful to our medical superintendent of Lumbini Zonal Hospital, Butwal for allowing me to use the data in this study. I would further like to thank all the health workers for their help in collecting information used in this study. I also acknowledge the secretarial help of Mr. Ram Malla from IPD, WHO, Butwal branch.

\section{Acknowledgement: None \\ Funding: None \\ Conflicting Interests: None \\ Permission from IRB: Yes}

\section{References}

1. Warrel DA. The clinical management of snakebite in south-east Asian region. South- east Asian J Trop Med and Pub Health 1999;30:1-84.

2. Guiterrez JM, Theakston RDG and Warrel DA. Confronting the neglected problem of snakebite envenoming: The need for a global partnership. PLOS Medicine 2006;3:727-31.

3. Rabies and envenoming: a neglected Public Health Issue. Report of Consultative meeting, $\mathrm{WHO} ; 10^{\text {th }}$ January 2001:3-11.

4. Currie BJ, Sutherland SK, Hudson BJ and Smith AMA. An epidemiological study of snakebite envenomation in Papua New Guinea. Med J Aust 1991;154:266-68.

5. Shah KB, Shrestha JM and Thapa CL. Snakebite management Guidelines. Aug 2003. DoHS-EDCD. Zoonoses Control Subsection; MoHP. Pp 1-10. 
6. Holve S. Envenomations: In Kliegman RM, Behrman RE, Jenson HB and Stanton BF.[eds]. Nelson Textbook of Pediatrics.18 $18^{\text {th }}$ edition, Saunders Company, Philadelphia; 2007:2932-38.

7. Bawasker HS and Bawasker PH. Envenoming by the common Krait and Asian cobra: clinical manifestations and their management in a rural setting. Wilderness and environmental medicine 2004;15:257-66.

8. Dixon RW and Haris JB. Nerve terminal damage by beta-Bungarotoxin. American $J$ Pathol 1999;154:447-54.

9. Read HA. Venomous bites and stings. In: Paediatric Emergencies. Black JA [ed]. Butterworths, London, 1979.

10. Heap BJ, Cowan GO. The epidemiology of snakebite presenting to British Military Hospital, Dharan during 1989. J R Army Med Corps, 1991; 137:123-25

11. Banerjee RN. Poisonous snakes in India, their venom, symptomatology and treatment. Progress in Clinical Medicine. $2^{\text {nd }}$ series. Ahuja MMS[ed], India: Arnold Heinmann, 1978;136-79.

12. Subrahmanyam BV. Modi's Medical Jurisprudence and toxicology. Butterworths, India1999. Section 2 ; Chapter6: 264-71.

13. Achyutam KC, Ramachandram L. Cardiotoxin of the Indian Cobra (Naja naja) is a pyrophosphate. $J$ Biosci 1982;3:149-56.

14. Jamieson R, Pearn J. An epidemiological and clinical study of snake-bites in childhood. Med $J$ Aust 1989;150:698-702.
15. Saborio P, Gonzalez M, Cambronero M. Snakebite accidents in children in Costa Rica: epidemiology and determination of risk factors in the development of abscess and necrosis [Spanish]. Toxicon 1998; 36(2):359-66.

16. Bewes P, Holmgren G. Snakebite in East and Southern Africa. Nytt. Om U-landshesovard 1997;2:4-8.

17. Harish R, Digra SK. Snakebite neurotoxicity: Reversal after 48 hours. Indian Pediatr 2001;44: 233.

18. Lovecchio F, DeBus DM. Snakebite envenomation in children: a 10-year retrospective review. Wilderness and Environmental Medicine, 2001; 12(3):184-89.

19. Parrish HM, Goldner JC, Silberg SL. Comparison between snakebite in children and adults. Pediatrics 1965;36:251-56.

20. Campbell $\mathrm{CH}$. A Clinical study of venomous snakebite in Papua (MD Thesis). Sydney: The University of Sydney, 1969:50-67.

21. Enwere GC, Oben HA, Jobarteh A. Snakebites in children in The Gambia. Annals of Tropical Paediatrics 2000;20(2):121-24.

22. Weber RA, White RR. Crotalidae envenomation in children. Ann Plast Surg 1993;31:141-45.

23. Clark RF, Seldon BS, Furbid B. The incidence of wound infection following crotalid envenomation. $J$ Emergency Med 1993;11:583-86.

24. Harbi $\mathrm{N}$ al. Epidemiological and clinical differences of snakebite among children and adults in Southwestern Saudi Arabia. J Accident Emergency Med 1999;16(6):428-30.

\section{How to cite this article?}

Shrestha BM. Outcomes of Snakebite Envenomation in Children. J Nepal Paediatr Soc 2011;31(3):192-197. 